\title{
EFEKTIVITAS METODE INQUIRY LEARNING TERHADAP HASIL BELAJAR IPA PADA TEMA ENERGI DAN PERUBAHANNYA
}

\author{
Imroatik Zahrotul Khoiriyah', Silviana Nur Faizah², Minahul Mubin ${ }^{3}$ \\ ${ }_{1,2,3}$ Universitas Islam Lamongan \\ e-mail:imroatik.zk@gmail.com ${ }^{1}$, silviana_nurfaizah@unisla.ac.id ${ }^{2}$, \\ minahul.mubin2013@gmail.com ${ }^{3}$
}

\begin{abstract}
Learning method is a way that is taken or used by the teacher to deliver a learning material in an effort to achieve the goals of a learning. Whereas IPA is one of the lessons that must involve students directly with the implementation of practicums to improve students' skills. In the process of learning science at SDN Tlogoagung, researchers found that learning outcomes were still low, the average score was $60 \%$ lower than the specified KKM, which was 75. This was possible because of the conventional learning process. The focus of the research that will be discussed in this study is about how the effectiveness of the inquiry learning method for learning outcomes and the skills of the science learning process in the matter of energy and its changes. The purpose of this study was to determine the effectiveness of the method of inquiry learning on learning outcomes and the skills of the science learning process on energy matter and its changes. The method used in this study is an experimental method using nonequivalent control group design. Data collection techniques used were interviews, tests, observation sheets and documentation. While the data analysis used is the validity test, reliability test, normality test, homogeneity test, assessment of the test, mean, achievement of learning outcomes, $N$-Gain, observation of basic process skills, and hypothesis testing using Independent samples t-test. From the results of the study it is known that the use of inquiry learning methods seen from the results of learning between the experimental class with the control class, while the average value of the experimental class post test is 87 while the average value of the control class post test is 79. Based on the results of hypothesis testing indicates that the value sig (2 tailed) smaller than 0.05 so $\mathrm{Ho}$ is rejected and $\mathrm{Ha}$ is accepted. This means that the inquiry learning method is effective on learning outcomes and the skills of the science learning process on energy matter and its changes.
\end{abstract}

Keywords: Inquiry Learning Method, Learning Outcomes, Science.

\section{A. Pendahuluan}

Pendidikan mempunyai peranan yang sangat penting terhadap kelangsungan berjalannya suatu bangsa. Pendidikan juga merupakan salah satu tempat yang dipercaya dapat mewujudkan peningkatan sumber daya manusia, sebagai manusia yang terdidik dan mempunyai keterampilan dalam suatu bidang. Pendidikan ialah suatu proses yang menggambarkan terbentuknya manusia yang utuh (Umar Tirtarahardja dan La Sulo, 2005). Berdasarkan Q.S. al-Imran (3): 189-191, pada dasarnya manusia dibekali oleh 
akal dan pikiran untuk mempelajari tanda-tanda kekuasaan Allah dengan mengamati bumi dan seisinya supaya bertambah Ilmu dan Taqwa terhadap Allah swt.

Bentuk ilmu pengetahuan yang mengamati tentang bumi dan seisinya diantaranya adalah Ilmu Pengetahuan Alam, dalam hakikatnya pembelajaran IPA di SD menekankan pada pemberian pengalaman belajar secara langsung melalui penggunaan dan pengembangan keterampilan proses dan sikap ilmiah. Pengajaran dikatakan baik jika proses yang terjadi memberikan hasil yang baik yaitu tercapainya tujuan pembelajaran. Salah satu cara agar tujuan pembelajaran dapat tercapai adalah dengan menggunakan metode pembelajaran yang sesuai dengan karakteristik siswanya (Susanto, 2013).

Pada tingkat sekolah dasar pembelajaran IPA dikemas dalam satu tema yang terintegrasi dengan mata pelajaran lain misalnya matematika, Bahasa Indonesia, dan lain sebagainya. Hal tersebut menjadi tantangan bagi guru dalam merancang pembelajaran tematik supaya tujuan pembelajaran dapat tercapai. Jika guru mengalami kesulitan dalam merancang dan melaksanakan pembelajaran yang menarik, maka akan terjadi permasalahan dalam pembelajaran seperti rendahnya hasil belajar, rendahnya motivasi, tidak terbentuknya keterampilan yang seharusnya dikuasai oleh siswa, dan permaslahan lainnya. Hal tersebut sebagaimana dialami oleh siswa kelas III SDN Tlogoagung yang hasil belajar IPA pada tema energy dan perubahannya menunjukkan 40\% dari 12 siswa belum tuntas KKM, dengan KKM yang telah ditentukan yaitu 75 .

Berdasarkan hasil observasi masalah pembelajaran siswa SDN Tlogo Agung dilatarbelakangi oleh beberapa hal diantaranya: (1) proses pembelajarannya hanya diarahkan pada kemampuan siswa untuk menghafal informasi, otak siswa dipaksa hanya untuk mengingat dan menimbun berbagai informasi, (2) guru tidak menggunakan media saat pembelajaran, (3) guru belum sepenuhnya melaksanakan pembelajaran secara aktif dan kreatif, (4) guru belum menggunakan metode yang tepat berdasarkan karakter materi pelajaran, (5) guru hanya terpaku pada buku teks sebagai satu-satunya sumber belajar mengajar serta, (6) guru masih menggunakan metode konseptual yang isinya guru menjelaskan pada siswa lalu siswa menulis atau mencatat penjelasan dari guru.

Guna mendukung tercapainya tujuan pembelajaran, perlu adanya perubahan pada pola-pola pembelajaran lama dengan pola pembelajaran baru yang lebih efektif dan efesien yakni dengan menguunakan metode pembelajaran inquiry learning, karena metode ini mengacu pada keingintahuan siswa, memotivasi mereka untuk melanjutkan pekerjaanya hingga mereka menemukan jawabannya. Siswa juga belajar memecahkan masalah secara mandiri dan keterampilan berpikir kritis karena mereka harus menganalisis dan menangani informasi (Asra, 2007).

Penerapan metode inquiry learning ini dibarengi dengan penjelasan yang bertujuan untuk memahamkan dan menumbukan aktivitas siswa dalam mata pelajaran 
IPA khususnya materi energi dan perubahannya. Hail ini sejalan dengan teori belajar menurut J.S Bruner yang menyatakan bahwa manusia sebagai pemroses, pemikir dan pencipta informasi.

J. S. Bruner dalam belajar IPA menekankan penanaman konsep dan dimulai dari benda yang konkrit secara intuitif. Kemudian, pada tahap-tahap yang lebih tinggi (sesuai dengan kemampuan siswa) konsep diajarkan dalam bentuk yang abstrak dan menggunakan notasi yang lebih umum yang dipakai dalam pembelajaran Ilmu Pengetahuan Alam (IPA) (Syofrianida, 2018).

Berdasarkan penelitian yang dilakukan oleh Devina Cici Ramawati (2015) yang berjudul "pengaruh penggunaan model pembelajaran inquiry learning terhadap hasil belajar IPA pada materi perubahan wujud benda siswa kelas III SDN Temas 01 Kota Batu" hasil penelitian tersebut menyimpulkan bahwa analisis uji t menggunakan nilai selisih antara nilai pretest dan nilai post test kedua kelas. Kelas yang menggunakan model pembelajaran inquiry learning memperoleh rata-rata 92,352 terdapat perbedaan rata-rata yang signifikan dengan kelas yang menggunakan model konvensional dengan rata-rata 75,882. Hal ini menunjukkan bahwa metode inquiry learning pada pembelajaran IPA materi perubahan wujud benda lebih baik dibandingkan dengan metode konvensional (Devina Cici Rahmawati, 2015).

Sedangkan menurut penelitian L Made Tangkas (2012) yang berjudul "pengaruh implementasi model pembelajaran inquiry terbimbing terhadap kemampuan pemahaman konsep dan keterampilan proses sains siswa kelas x SMAN 3 Amlapura" hasil penelitian tersebut menyimpulkan Pertama, terdapat perbedaan yang signifikan hasil pemahaman konsep dan keterampilan proses sains antara kelompok siswa dengan model inkuiri terbimbing dan kelompok siswa dengan model pembelajaran langsung ( $\mathrm{F}$ $=10,349 ; \mathrm{p}<0,05)$. Kedua, terdapat perbedaan pemahaman konsep antara kelompok siswa dengan model inkuiri terbimbing dan kelompok siswa dengan model pembelajaran langsung (Fhitung $=12,183$; Ftabel $=3,920$ ). Ketiga , terdapat perbedaan keterampilan proses sains antara kelompok siswa dengan model inkuiri terbimbing dan kelompok siswa dengan model pembelajaran langsung (Fhitung $=16,756$; Ftabel $=$ 3,920). Jadi, rata-rata pemahaman konsep siswa yang mengikuti model pembelajaran inquiri terbimbing $(X=65,57)$ lebih besar dari rata-rata kelompok siswa yang mengikuti model pembelajaran langsung ( $\mathrm{X}=57,81)$ (Tangkas, 2012).

Berdasarkan ulasan di atas dapat disimpulkan bahwa metode inquiry dapat dijadikan sebuah alternatif yang dilakukan pendidik untuk meningkatkan hasil belajar IPA kelas III materi Energi dan Perubahannya. Karena, metode inquiry learning merupakan proses pembelajaran yang bervariasi dan meliputi kegiatan-kegiatan megobservasi, merumuskan pertanyaan yang relevan, mengevaluasi buku dan sumbersumber informasi lain secara kritis, merencanakan penyelidikan, me-review apa yang 
telah diketahui, melaksanakan eksperimen dengan menggunakan alat untuk memperoleh data, menganalisis dan mengintrepetasi data serta membuat prediksi dan mengomunikasikan hasilnya (Susanto, 2013). Sehingga menjadi penting dilakukannya sebuah penelitian tentang efektifitas metode inquiry learning terhadap hasil belajar IPA pada Tema Energi dan perubahannya pada siswa kelas III SDN Tlogoagung.

\section{Metode Inquiry Learning}

Metode inquiry merupakan proses bervariasi dan meliputi kegiatan-kegiatan mengobservasi, merumuskan pertanyaan yang relevan, mengevaluasi buku dan sumbersumber informasi lain secara kritis, merencanakan penyelidikan atau investigasi, mereview apa yang telah diketahui, melaksanakan percobaan atau eksperimen dengan menggunakan alat untuk memperoleh data, menganalisis dan mengitrepetasi data, serta membuat prediksi dan mengomunikasikan hasilnya (Asra, 2007).

Ciri pembelajaran inquiry learning yaitu pembelajarannya menekankan pada semua pendidik agar menerapkan kegiatan pembelajaran yang menekankan proses dalam pemahaman materi pelajaran. Proses pembelajaran inquiry juga diawali dengan pertanyaan yang dapat menumbuhkan keingintahuan siswa dalam melihat fenomena alam.

Ada beberapa tujuan pembelajaran inquiry learning diantaranya yaitu: (1) Mengembangkan keinginan dan motivasi siswa untuk mempelajari prinsip dan konsep sains, (2) Mengembangkan keterampilan ilmiah siswa sehingga mampu bekerja seperti layaknya seorang ilmuan, (3) Membiasakan siswa bekerja keras untuk memperoleh pengetahuan (Susanto, 2013).

Beberapa macam metode inquiry learning yaitu:

(1) inquiry terbimbing, (2) Inquiry bebas, (3) Inquiry bebas dimodifikasi Pada penelitian ini menggunakan metode inquiry learning jenis terbimbing, pelaksanaan metode inquiry terbimbing dilakukan oleh siswa berdasarkan petunjuk atau arahan dari guru. Sebagai suatu metode pembelajaran yang dipercaya mempunyai banyak kelebihan, namun tidak dapat disangkal bahwasannya metode inquiry learning juga terdapat beberapa kekurangannya. Adapun kelebihan dari Metode inquiry learning yaitu: (1) Metode pembelajaran ini mengacu pada keingintahuan siswa, (2) Memotivasi mereka untuk melanjutkan pekerjaanya hingga mereka menemukan jawabannya, (3) Siswa juga belajar memecahkan masalah secara mandiri dan keterampilan berpikir kritis karena mereka harus menganalisis dan menangani informasi, (4) Menumbuhkan aktivitas siswa (Asra, 2007). Sedangkan kekurangan dari metode inquiry learning yaitu: (1) Guru merasa gagal mendeteksi masalah dan adanya kesalah pahaman antara guru dengan siswa, (2) Menyita waktu banyak, (3) Guru dituntut mengubah kebiasaan mengajar yang umumnya sebagai pemberi informasi menjadi fasilitator, motivator dan 
membimbing siswa belajar dengan baik, (4) Tidak semua siswa mampu melakukan penemuan, tidak berlaku untuk semua topik.

Setelah dijabarkan kelebihan dan kekurangan dari Metode Inquiry Learning diatas. Adapun Langkah-langkah pelaksanaan pembelajaran metode inquiry learning yaitu: (1) Orientasi, (2) Merumuskan masalah, (3) Mengajukan hipotesis, (4) Mengumpulkan data, (5) Menguji hipotesis, (6) Merumuskan kesimpulan (Sanjaya, 2018).

\section{Hasil Belajar}

Menurut Nawawi, Hasil Belajar adalah tingkat keberhasilan siswa dalam mempelajari materi pelajaran di sekolah yang dinyatakan dalam bentuk skor yang diperoleh dari hasil tes mengenai sejumlah pelajaran tertentu. Pendapat tersebut memperkuat pengertian dari Hasil belajar yakni perubahan-perubahan yang terjadi pada diri seorang siswa, baik yang bersangkutan dengan ranah kognitif, afektif dan psikomotor sebagai hasil dari kegiatan belajar (Susanto, 2013).

Menurut Purwanto hasil belajar merupakan perubahan perilaku sebagai dampak dari belajar sedangkan menurut sukmadinata hasil belajar adalah bentuk pemekaran dari bentuk kecakapan-kecakapan potensial yang dimiliki seseorang tersebut tercermin pada tiga aspek, kognitif, afektif, dan psikomotorik (Mubin, 2018) .

Kemampuan seorang siswa akan dilihat dari hasil belajarnya, jika hasil belajarnya relatif baik dan memenuhi semua komponan yang dibutuhkan maka tujuan pembelajaran sudah tercapai. Untuk mengetahui hasil belajar siswa sesuai atau tidaknya dengan tujuan pembelajaran maka perlu adanya sebuah evaluasi pembelajaran.

Menurut Bloom dalam Nana Sudjana hasil belajar dibagi menjadi tiga macam, yaitu ranah kognitif, afektif dan psikomotorik (Sudjana, 2014). Dalam penelitian ini ranah yang diteliti adalah ranah kognitif yang fokus pada pemahaman konsep siswa pada pembelajaran IPA pada Tema Energi dan Perubahannya.

\section{IPA}

Pembelajaran Ilmu Pengetahuan Alam di SD menekankan pada pemberian pengalaman belajar secara langsung melalui penggunaan dan pengembangan keterampilan proses dan sikap ilmiah. Pengajaran dikatakan baik jika proses yang terjadi memberikan hasil yang baik yaitu tercapainya tujuan pembelajaran. Salah satu cara agar tujuan pembelajaran dapat tercapai adalah dengan menggunakan metode pembelajaran yang sesuai dengan karakteristik siswanya.

Adapun tujuan Ilmu Pengetahuan Alam di SD dalam Badan Nasional Standar Pendidikan, yaitu untuk: (1) Memperoleh keyakinan terhadap kebesaran Tuhan yang Maha Esa berdasarkan keberadaan, keindahan dan keteraturan alam ciptaannya., (2) 
Mengembangjan pengetahuan dan pemahaman konsep IPA yang bermanfaat dan dapat diterapkan dalam kehidupan sehari-hari, (3) Mengembangkan rasa ingin tahu, sikap positif dan kesadaran tentang adanya hubungan yang saling memengaruhi antara IPA, lingkungan, teknologi dan masyarakat, (4) Mengembangkan keterampilan proses untuk menyelidiki alam sekitar, memecahkan masalah dan membuat keputusan, (5) Meningkatkan kesadaran untuk berperan serta dalam memelihara, menjaga dan melestarikan lingkungan, (6) Meningkatkan kesadaran untuk menghargai alam dan segala keteraturannya sebagai salah satu ciptaan Tuhan, (7) Memperoleh bekal pengetahuan konsep dan keterampilan Ilmu Pengetahuan Alam sebagai dasar untuk melanutkan pendidikan ke SMP (Amalia Sapriati, 2014).

Energi adalah kemampuan untuk melakukan kerja atau membuat sesuatu terjadi. Kita tidak mungkin hidup tanpa energi. Sepanjang hidup manusia selalu mencari berbagai sumber energi. Energi di perlukan untuk menggerakkan sepeda motor, mobil, pesawat terbang, kereta dan kendaraan lainnya. Manusia, hewan, dan tumbuhan dapat melangsungkan hidup karena adanya makanan sebagai sumber tenaga. Orang dapat bergerak karena mempunyai energi yang cukup.

Bentuk energi bermacam-macam, yaitu: energi panas dan cahaya, energi gerak, energi listrik, energi bunyi dan energi kimia. Energi berasal dari sumber energi. Beberapa sumber energi diantaranya: (1) Matahari, (2) Air, (3) Angin, (4) Kayu bakar, (5) Makanan, (6) Minyak Bumi dan Minyak Gas, (7) Listrik (Amalia Sapriati, 2014).

\section{B. Metode}

Mengacu pada tujuan penelitian yaitu mengetahui efektifitas metide inquiry learning, maka penelitian ini menggunakan metode kuantitatif dengan desain Quasi Eksperimental tipe Nonequivalent Control Group Design yangmana menggunakan dua kelompok yaitu kelompok eksperimen dan kontrol. Kedua kelompok tersebut adalah siswa kelas III SDN Tlogoagung sebagai kelas eksperimen yang berjumlah 12 siswa dan siswa kelas III SDN Kedungmegarih sebagai kelas kontrol yang berjumlah 9 siswa. Adapun desain penelitian ini terlihat pada gambar 1 .

\section{Gambar 1 Desain Penelitian Eksperimen}

Keterangan :

\begin{tabular}{|lll|}
\hline $\mathrm{O}_{1}$ & $\mathrm{X}$ & $\mathrm{O}_{2}$ \\
\hline $\mathrm{O}_{3}$ & $\mathrm{O}_{4}$ \\
\hline
\end{tabular}

$\mathrm{O}_{1}$ : Hasil belajar kelas eksperimen sebelum penerapan metode inquiry learning (Pre Test)

$\mathrm{O}_{2}$ : Hasil belajar kelas eksperimen setelah penerapan metode inquiry learning (Post Test) 
O3 : Hasil belajar Kelas kontrol sebelum penerapan metode ceramah (Pre Test)

O4 : Hasil belajar Kelas kontrol setelah penerapan metode ceramah (Post Test)

$\mathrm{X}$ : Metode pembelajaran inquiry learning

Penelitian ini dilakukan pada tahun ajaran 2018/2019 dengan beberapa teknik pengumpulan data yaitu dengan wawancara, tes dan dokumentasi. Adapun instrumen penelitian sebelum digunakan telah diuji validitas dan reliabilitasnya dengan menggunakan validasi konstruk (ahli). Instrument tes yang digunakan berupa soal pilihan ganda yang berjumlah 25 soal.

Pengolahan data hasil belajar siswa diawali dengan soal pre-test dan post-test yang kemudian hasilnya dirata-rata untuk mengetahui hasil sebelum dan sesudah diterapkannya metode inquiry learning. Selanjutnya untuk mengetahui sampel populasi berdistribusi normal maka dilakukan uji normalitas dengan menggunakan metode Lilifors yang merupakan penyempurnaan dari metode kolmogorov-smirnov sehingga sifatnya lebih menyederhanakan. Uji pendekatan terhadap distribusi normal menggunakan metode Lilifors yang merupakan penyempurnaan dari metode kolmogorov-smirnov sehingga sifatnya lebih menyederhanakan dengan bantuan SPSS 25.

Adapun dasar pengambilan keputusan dalam melakaukan uji normalitas Kolmogrov-sminorv yakni: (a) Jika nilai signifikasi (sig.) > 0,05 maka data penelitian berdistribusi normal, (b) Jika nilai signifikasi (sig.) $<0,05$ maka data penelitian tidak berdistribusi normal.

Setelah uji normalitas dilakukan selanjutnya dilakuakn uji homogenitas untuk mengetahui sama atau tidaknya variansi-variansi dari dua buah distribusi atau lebih (Irianto, 2008). Uji homogenitas dilakukan dengan berbantuan SPSS 25 dengan dasar pengambilan keputusan jika nilai nilai signifikasi (sig.) > 0,05 maka data dinyatakan homogen.

Efektivitas metode pembelajaran inquiry learning terhadap hasil belajar maka dilakukan uji hipotesis menggunakn uji t (Independent-Samples t-Test) berbantuan SPSS 25 dengan dasar keputusan jika nilai sig.(2-tailed) > 0,05 maka $\mathrm{H}_{\mathrm{a}}$ ditolak dan $\mathrm{H}_{\mathrm{o}}$ diterima dan jika nilai sig. (2-tailed) $<0,05$ maka $\mathrm{H}_{\mathrm{a}}$ diterima dan $\mathrm{H}_{\mathrm{o}}$ ditolak.

\section{Hasil dan Pembahasan}

Setelah instrumen penelitian divalidasi tiga validator ahli dan dinyatakan valid dan reliabel, selanjutnya instrumen penelitian diterapkan pada siswa kelas III SDN Tlogoagung. Berdasarkan uji normalitas diperoleh hasil sebagai berikut. 
Tabel 1. Uji Normalitas

\begin{tabular}{|l|l|r|r|r|r|r|r|}
\hline \multicolumn{2}{|c|}{ Tests of Normality } \\
\hline \multirow{2}{*}{} & Kelas & \multicolumn{2}{|c|}{ Kolmogorov-Smirnova } & \multicolumn{3}{c|}{ Shapiro-Wilk } \\
\cline { 2 - 8 } & Statistic & Df & \multicolumn{1}{c|}{ Sig. } & Statistic & Df & \multicolumn{1}{c|}{ Sig. } \\
\hline \multirow{2}{*}{ Hasil } & pretes eksperimen &, 128 & 12 &, $200^{*}$ &, 932 & 12 &, 400 \\
\cline { 2 - 8 } & pretest kontrol &, 147 & 9 &, $200^{*}$ &, 961 & 9 &, 813 \\
\hline \multirow{2}{*}{ *. This is a lower bound of the true significance. } \\
a. Lilliefors Significance Correction
\end{tabular}

Hasil uji normalitas dengan berbantu SPSS 25 pada tabel diatas dapat diketahui bahwa nilai Sig lebih besar dari 0,05 dengan demikian maka data variabel yang digunakan dalam penelitian ini berdistribusi normal.

Uji homogenitas digunakan untuk mengetahui apakah kedua kelas memiliki varians yang sama (homogen). Berikut data hasil uji homogenitas.

Tabel 2. Uji Homogenitas

\begin{tabular}{|l|l|r|r|r|r|}
\hline \multicolumn{7}{|c|}{ Test of Homogeneity of Variance } \\
\hline \multirow{3}{*}{ Hasil } & Levene Statistic & df1 & \multicolumn{1}{c|}{ df2 } & \multicolumn{1}{c|}{ Sig. } \\
\cline { 2 - 6 } & Based on Mean & 4,228 & 1 & 19 &, 054 \\
\cline { 2 - 6 } & Based on Median & 3,952 & 1 & 19 &, 061 \\
\cline { 2 - 6 } & $\begin{array}{l}\text { Based on Median and with } \\
\text { adjusted df }\end{array}$ & 3,952 & 1 & 15,280 &, 065 \\
\cline { 2 - 6 } & Based on trimmed mean & 4,279 & 1 & 19 &, 052 \\
\hline
\end{tabular}

Hasil uji homogenitas dengan berbantu SPSS 25 pada tabel 2 dapat diketahui bahwa nilai Sig lebih besar dari 0,05 dengan demikian maka data variabel yang digunakan dalam penelitian ini homogen.

Tes hasil belajar yang diberikan sebelum metode inquiry learning dilaksanakan (pre-test) dan sesudah dilaksanakan (post-test). Adapun hasil belajar dengan penerapan metode inquiry learning secara menyeluruh disajikan pada Gambar 1. 


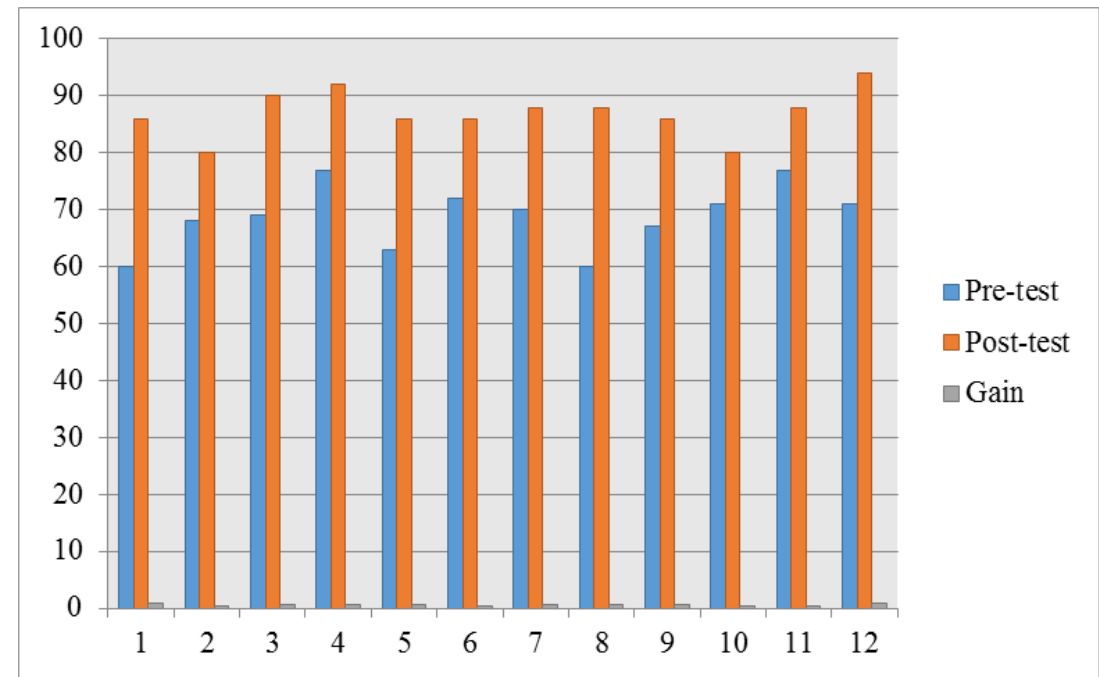

Gambar 1 Hasil Pre-test Dan Post-test Kelas Eksperimen

Berdasarkan tabel 3 hasil belajar kelas eksperimen meningkat, hal itu dapat dilihat dari pemerolehan nilai pre tes, adapun rata-rata nilai pre tes adalah 69 dan rata-rata nilai post tes adalah 87. Berdasakan kriteria hasil belajar maka nilai post tes kelas eksperimen termasuk dalam kriteria sangat baik. Sehingga hasil belajar kelas eksperimen mengalami kenaikan sebesar 22 pada pembelajaran IPA materi energi dan perubahannya dengan menggunakan metode inquiry learning.

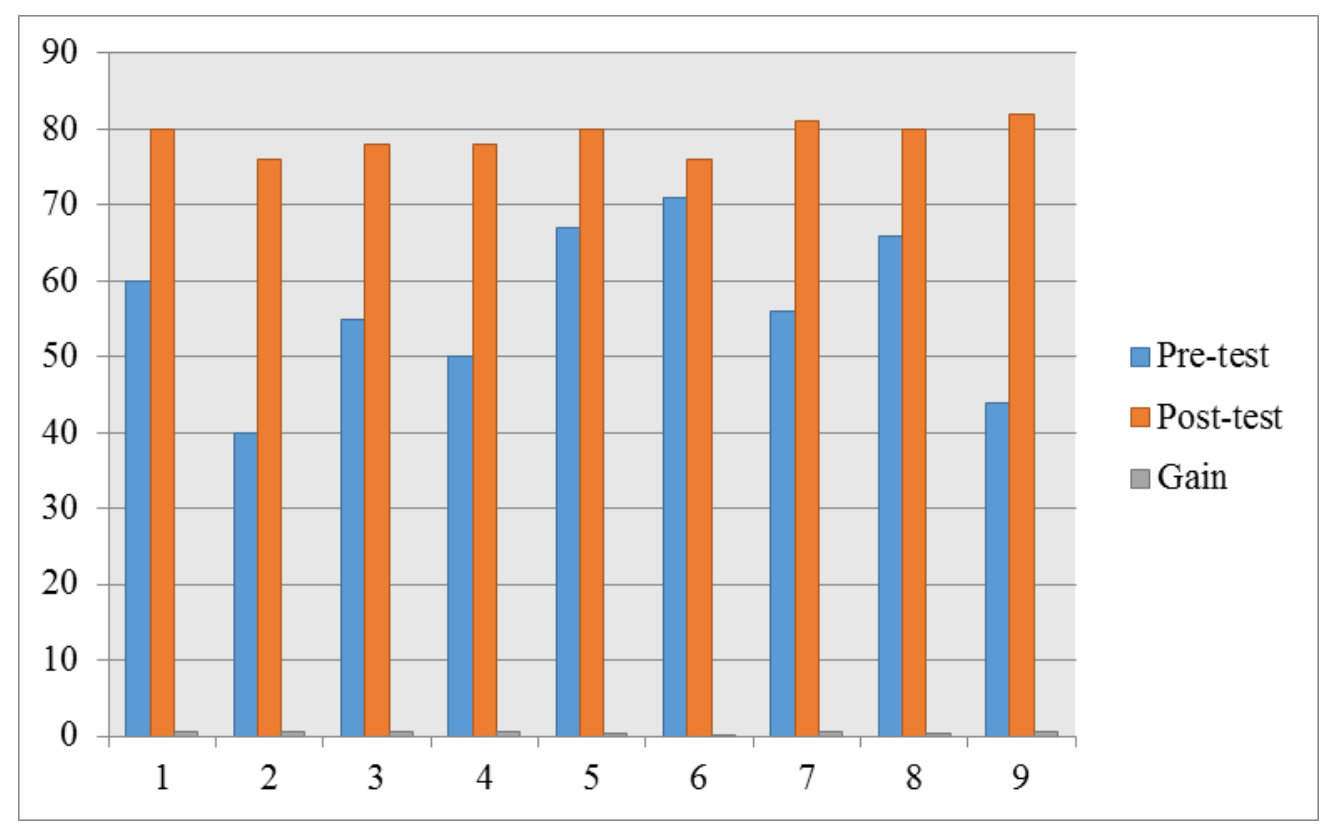

Gambar 2. Diagram Hasil Pre-test Dan Post-test Kelas Kontrol 
Sedangkan hasil belajar kelas konrol memperoleh rata-rata nilai pre tes sebesar 57 dan rata-rata nilai post tes sebesar 79 . Berdasakan kriteria hasil belajar maka nilai post tes kelas kontrol termasuk dalam kriteria baik. sehingga hasil belajar kelas kontrol mengalami kenaikan sebesar 21 pada pembelajaran IPA materi energi dan perubahannya dengan menggunakan metode ceramah.

Disimpulkan bahwa hasil belajar kelas ekperimen mengalami peningkatan yang lebih tinggi dibanding kelas kontrol, hal itu dibuktikan dengan besar peningkatan kelas eksperimen mencapai 22 sedangkan kelas kontrol hanya sebesar 21.

Uji hipotesis menggunankan nilai Post tes kelas eksperimen dan post-test kelas kontrol, hal ini bertujuan untuk mengetahui efektivitas dari penerapan motode inquiry learning dan untuk menjawab apakah $\mathrm{H}_{\mathrm{a}}$ diterima atau ditolak. Berikut hasil uji hipotesis dengan berbantu SPSS 25.

Tabel 3 Uji Hipotesis

\begin{tabular}{|c|c|c|c|c|c|c|c|c|c|c|}
\hline \multicolumn{11}{|c|}{ Independent Samples Test } \\
\hline & & \multicolumn{2}{|c|}{$\begin{array}{c}\text { Levene's Test } \\
\text { for Equality of } \\
\text { Variances }\end{array}$} & \multicolumn{7}{|c|}{ t-test for Equality of Means } \\
\hline & & \multirow[b]{2}{*}{$\mathrm{F}$} & \multirow[b]{2}{*}{ Sig. } & \multirow[b]{2}{*}{$\mathrm{t}$} & \multirow[b]{2}{*}{ df } & \multirow{2}{*}{$\begin{array}{l}\text { Sig. (2- } \\
\text { tailed) }\end{array}$} & \multirow{2}{*}{$\begin{array}{l}\text { Mean } \\
\text { Differ } \\
\text { ence }\end{array}$} & \multirow{2}{*}{$\begin{array}{l}\text { Std. Error } \\
\text { Difference }\end{array}$} & \multicolumn{2}{|c|}{$\begin{array}{c}95 \% \text { Confidence } \\
\text { Interval of the } \\
\text { Difference } \\
\end{array}$} \\
\hline & & & & & & & & & Lower & Upper \\
\hline \multirow[t]{2}{*}{ hasil } & $\begin{array}{l}\text { Equal } \\
\text { variances } \\
\text { assumed }\end{array}$ & 1,667 & ,212 & 5,284 & 19 &, 000 & 8,000 & 1,514 & 4,831 & 11,169 \\
\hline & $\begin{array}{l}\text { Equal } \\
\text { variances } \\
\text { not assumed }\end{array}$ & & & 5,767 & 17,170 &, 000 & 8,000 & 1,387 & 5,076 & 10,924 \\
\hline
\end{tabular}

Berdasarkan perhitungan data yang dianalisis menggunakan Independent Samples t-Test. Dengan bantuan SPSS 25. Pada tabel 4 menunjukan bahwa nilai Sig (2-tailed) yakni 0,000 lebih kecil dari 0,05 artinya $\mathrm{H}_{\mathrm{a}}$ diterima dan $\mathrm{H}_{0}$ ditolak, sehingga diperoleh hasil, Metode inquiry learning Efektif Hasil Belajar IPA Pada Materi energi dan perubahannya Siswa Kelas III SDN Tlogoagung. 


\section{Simpulan}

Penelitian ini bertujuan untuk mengetahui adanya perbedaan penggunaan metode Inquiry Learning terhadap hasil belajar dan keterampilan proses belajar siswa pada mata pelajaran IPA materi energi dan perubahannya. Berdasarkan hasil analisis dengan menggunakan uji t independent sample t-test diperoleh hasil Sig. (2-tailed) $\leq 0,005$, dengan nilai Sig. (2-tailed) adalah 0,00, sehingga dapat dikatakan bahwa penggunaan metode pembelajaran Inquiry Learning efektif digunakan pada hasil belajar dan keterampilan pproses IPA materi Energi dan kegunaannya.

Hasil analisis uji hipotesis dengan uji t menunjukkan bahwa terdapat hubungan yang signifikan antara pembelajaran Inquiry Learning pada mata pelajaran IPA materi energi dan perubahannya terhadap hasil belajar dan keterampilan proses siswa. Ratarata hasil jawaban soal siswa pada waktu pre-test dengan pembelajaran konvensional dibandingkan pada saat postest dengan pembelajaran Inquiry Learning rata-rata nilai hasil jawaban soal mengalami kenaikan.

\section{Daftar Rujukan}

Amalia Sapriati. (2014). Pembelajaran IPA di SD. Tanggerang Selatan: Universitas Terbuka. Asra, S. dan. (2007). Metode Pembelajaran. Bandung: CV Wacana Prima.

Devina Cici Rahmawati. (2015). Pengaruh penggunaan model pembelajaran inquiry learning terhadap hasil belajar IPA pada materi perubahan wujud benda siswa kelas III SDN Temas 01 Kota Batu. Universitas Muhammadiyah Malang.

Irianto, A. (2008). Statistik Konsep dasar dan Aplikasinya. Jakarta: Prenada Media Group.

Mubin, S. N. F. dan M. (2018). Pengaruh Modul Tematik Berbasis Integrasi Islam dan Sainspada tema Energi dan Perubahannya Terhadap hasil Belajar Siswa MI Murni Sunan Drajat Lamongan. Jurnal Penelitian Pendidikan IPA, 3(2), 72-76.

Sanjaya, W. (2018). Perencanaan dan desain system pembelajaran. Jakarta: Kencana.

Sudjana, N. (2014). Penilaian Hasil Proses Belajar Mengajar (VI). Bandung: PT Remaja Rosdakarya.

Susanto, A. (2013). Teori Belajar dan Pembelajaran di Sekolah Dasar. Jakarta: Prenadamedia Group.

Syofrianida, S. (2018). Belajar dan Pembelajaran. Yogyakarta: Parama Ilmu.

Tangkas, L. M. (2012). Pengaruh Implementasi Model Pembelajaran Inquiry Terbimbing Terhadap Kemampuan Pemahaman Konsep dan Keterampilan Proses Sains Siswa Kelas X SMAN 3 Amlapura. Universitas Pendidikan Ganesha.

Umar Tirtarahardja dan La Sulo. (2005). Pengantar Pendidikan. Jakarta: Rineka Cipta. 